\title{
Influence of Vegetable Inclusion in Rice Monoculture on Soil Organic Matter Quality under Sub-Tropical Climate
}

\author{
M.D. Abdul Kader, S. Sleutel, S. A. Begum, S. De Neve \\ Department of Soil Management, Ghent University \\ Coupure Links 653, 9000 Gent, Belgium
}

Keywords: Soil Organic Matter Quality, Physical Fractionation, Cropping Pattern, Rice

Monoculture, Vegetable soil, Sub-Tropical Soil

\begin{abstract}
Soil organic matter (SOM) quality and its decomposability are influenced by cropping pattern. In particular, little is known on the specific difference in SOM quality under rice monoculture or combination of vegetables with rice culture. Therefore, four pairs of fields having vegetable-rice and rice-rice cropping pattern were selected from four different locations in Bangladesh, covering floodplain and terrace soils. Soils were first physically fractionated into particulate organic matter (POM) and silt and clay sized OM. The silt and clay sized OM was further chemically fractionated by oxidation with $6 \% \mathrm{NaOCl}$ to isolate an oxidationresistant $\mathrm{OM}$ fraction, followed by extraction of mineral bound $\mathrm{OM}$ with $10 \% \mathrm{HF}$ (HF-res OM). The results show that there is a small increase in POM in vegetablerice compared with monoculture rice soils. Among the fractions, a very large share of $\mathrm{OM}$ resided in $\mathrm{NaOCl}$ oxidizable $\mathrm{OC}$ and $\mathrm{N}$ in vegetable-rice soils. The silt and clay organic $\mathrm{N}$ was found to be more susceptible to $\mathrm{NaOCl}$ treatment compared with organic carbon (OC). Both the HF-extracted (HF-ex) and HF-res OC and N were found to be lower in vegetable-rice soils than in monoculture rice soils. Results from both physical and chemical fraction of SOM suggest that SOM accumulated in vegetable-rice cropping pattern are more labile than the solely rice based cropping pattern and prone to decompose quickly in any change of land use.
\end{abstract}

\section{INTRODUCTION}

Soil quality is largely regulated by soil organic matter (SOM). Most soil properties such as soil structure, water retention capacity, and diversity and activity of soil organisms are greatly influenced by the quantity and quality of SOM (Reeves, 1997). In addition, the role of soil organic carbon (SOC) within the terrestrial carbon budget as a sink for atmospheric $\mathrm{CO}_{2}$ has received special attention (Lal, 2004; 2007). Therefore, SOM is considered to be a key attribute of soil quality, environmental quality, and agronomic sustainability (Reeves, 1997; Carter, 2002). SOM and particularly labile SOM fractions are dynamic properties that respond to changes in soil management (Zhang et al, 2006).

There is an increasing trend of change in land use from paddy rice to upland vegetables during dry winter period in Bangladesh. As a consequence, there was an increase of vegetable cultivation area from 244000 to 453000 ha between 1996 and 2007 with an average annual growth rate of $2.7 \%$ (FAO, 2009). This land use change was driven by several factors. Firstly, cultivation of vegetable in combination with rice during winter period is more profitable compared with solely rice based cropping pattern as the price and yield of vegetables is much higher than the rice. Secondly, there is a growing 
demand for fresh vegetables in market to meet the demand by rapidly growing urban areas and urban population. Thirdly, government in Bangladesh is encouraging farmers to cultivate diversified crop instead of monoculture rice to sustain soil fertility and to increase their income. Soil management practices in vegetable production are totally different than the rice cultivation. Rice is mostly grown under flooded conditions in bunded fields (paddies) with less fertilization and manuring. Farmers usually keep a very small part of rice straw (varied from 5 to $15 \mathrm{~cm}$ ) in their fields after rice harvest including rice roots. In rice monoculture, land remains dry or flood fallowed during the turnaround period between two rice crops. Following these cultural practices, two or three crops of rice in sequence are grown in a solely rice based cropping pattern. On the other hand, vegetables are grown in dry land condition with intensive fertilization and manuring (Chen et al, 2004). In some vegetable fields, farmers use mulching to maintain soil temperature and moisture. Farmers also leave some crop residues in vegetable fields after harvest. Therefore, the accumulation and stabilization process of SOM may be largely different between vegetable-rice and monoculture rice cropping pattern and this could resulted different in SOM quality. Therefore, this study attempts to examine to what extent the vegetable based cropping patterns are different from traditional monoculture rice cropping patterns in terms of SOM quality.

\section{MATERIAL AND METHODS}

\section{Site description and soils}

Four pairs of fields having vegetable-rice and rice-rice cropping pattern were selected from four different locations of Bangladesh covering two major soil types, namely very younger floodplain and older highly weathered terrace soil. The locations were: Chandpur (Fields 1 and 2), Rangpur (Fields 3 and 4), Bogra (Fields 5 and 6) and Netrokona (Fields 7 and 8). This cropping pattern has been following for the selected fields since last 10-15 years. However, some years farmers keep fallow their lands or change the cropping pattern due to unfavourable environmental conditions such as flooding or poor marketing situation such as very low price. Fifteen soil samples were taken at each plot by means of an auger $(\varnothing 2.5 \mathrm{~cm})$ within a $25 \mathrm{~m} \times 40 \mathrm{~m}$ rectangle. Basic properties of the soils are given in Table 1. The four vegetable-rice grown fields were each paired with monoculture rice grown fields with comparable soil type and texture, because of the major influence of these factors on $\mathrm{C}$ and $\mathrm{N}$ dynamics in soil. Bangladesh has a subtropical monsoon climate with a hot and rainy summer and a pronounced dry season in the cooler months. The annual mean temperature and precipitation of Bangladesh are $25^{\circ} \mathrm{C}$ and $2320 \mathrm{~mm}$, respectively. Vegetables are grown in Bangladesh mainly during the dry and cooler winter.

\section{Fractionation of soil organic matter}

An ultra sonication-sedimentation method was used to physically fractionate particulate organic matter (POM) from the silt and clay sized SOM based on the procedure outlined by Amelung et al. (1997). Whole soil samples were dispersed at a low level of ultra sonication energy $\left(60 \mathrm{~J} \mathrm{ml}^{-1}\right)$ to breakdown the macro and micro aggregates. The silt and clay fraction $(<50 \mu \mathrm{m})$ was then subjected to a chemical fractionation procedure according to Mikutta et al. (2006) and slightly modified by Sleutel et al. (2009), which involves sequential oxidation with $6 \% \mathrm{NaOCl}$ and mineral extraction with $10 \% \mathrm{HF}$. The procedure results in the isolation of $1^{\circ}$ a chemically stable $6 \% \mathrm{NaOCl}$ resistant $\mathrm{SOM}$ fraction 
composed of mineral-protected as well as biochemically recalcitrant $\mathrm{OM}$ and $2^{\circ}$ a biochemically non-bound recalcitrant SOM fraction (Fig 1). A $5 \mathrm{~g}$ silt and clay sized sample was reacted three times for $6 \mathrm{~h}$ with $50 \mathrm{ml} 6 \% \mathrm{NaOCl}$ adjusted to $\mathrm{pH} 8.0$ inside $85 \mathrm{ml}$ nalgene centrifuge tubes. Samples were centrifuged and decanted in between oxidation cycles and were ultimately washed one time with $1 \mathrm{M} \mathrm{NaCl}$ and three times with deionized $\mathrm{H}_{2} \mathrm{O}$. After drying and weighing, a sub sample was used for total $\mathrm{C}$ and $\mathrm{N}$ analysis. Then, $3 \mathrm{~g}$ of the oxidation residue was treated four times with $20 \mathrm{ml} 10 \% \mathrm{HF}$ in order to dissolve and remove mineral constituents and mineral-bound OM. Extraction residues were washed five times with deionized $\mathrm{H}_{2} \mathrm{O}$ to remove salts and residual $\mathrm{HF}$ and were dried and weighed. Chemical fractionations were carried out in twofold.

\section{Carbon and nitrogen analysis}

Both the $\mathrm{OC}$ and $\mathrm{N}$ content from all the fractions were determined by elemental analysis (Variomax CNS-analyzer, Elementar Analysesysteme, Germany). Absolute amounts of $\mathrm{C}$ and $\mathrm{N}$ in the different fractions expressed in $\mathrm{g} \mathrm{kg}^{-1}$ were calculated from the relative dry matter weight of each fraction and its percentage of $\mathrm{C}$ and $\mathrm{N}$.

\section{Statistical analysis}

All statistical tests were conducted with the SPSS 15.0 package (SPSS Inc., Chicago). ANOVA ( $\mathrm{P}=0.05)$ was used to test differences in the SOC and $\mathrm{N}$ distributions over physical and chemical fractions between vegetable-rice and monoculture rice soils.

\section{RESULT AND DISCUSSION Physical fractions}

The absolute as well as relative amounts of OC and $\mathrm{N}$ in POM fraction were not found to be consistently either higher or lower with a vegetable-rice cropping pattern as compared with monoculture rice soils (Table 2). However, when averaged over all four locations, a higher amounts of POM OC and $\mathrm{N}$ were observed on an absolute as well as relative basis in soils having a vegetable-rice cropping pattern (on average 3.05 and $0.24 \mathrm{~g}$ OC and $\mathrm{N} \mathrm{kg}^{-1}$ soil, respectively accounting 30.5 and $22.5 \%$ of SOC and total $\mathrm{N}$, respectively) compared with the monoculture rice soils (on average 2.9 and $0.2 \mathrm{~g}$ OC and $\mathrm{N} \mathrm{kg}^{-1}$ soil, respectively accounting 29.5 and $20.0 \%$ of SOC and total $\mathrm{N}$, respectively) though the differences were not significant. The C:N ratio in POM fraction was smaller in soils having vegetable-rice cropping pattern (on average 14.1) compared with monoculture rice soils (on average 15.6). As a consequence of the relatively higher contribution of the OC and $\mathrm{N}$ in the POM fraction, the absolute as well as relative content of silt and clay $\mathrm{OC}$ and $\mathrm{N}$ was lower in soils with vegetable-rice cropping pattern (on average 6.78 and $0.79 \mathrm{~g}$ OC and $\mathrm{N} \mathrm{kg}^{-1}$ soil, respectively accounting 69.5 and $77.5 \%$ of SOC and total $\mathrm{N}$, respectively) compared with the monoculture rice soils (on average 7.17

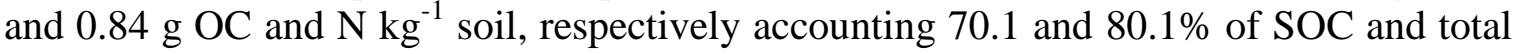
$\mathrm{N}$, respectively). A larger relative proportion of silt + clay associated $\mathrm{N}(78.8 \pm 8.9 \%$ of total $\mathrm{N})$ compared with silt + clay associated OC $(69.9 \pm 7.2 \%$ of the total OC) was observed for all the sites, reflecting the often reported enrichment of $\mathrm{N}$ with decreasing particle size (Leinweber and Schulten, 1995, Kader et al, 2010a).

Higher POM OC and $\mathrm{N}$ content in soils having vegetable-rice cropping pattern with low $\mathrm{C}: \mathrm{N}$ ratios could be attributed to the farmers practice keeping vegetable crop residues in their fields after harvest. In addition, sometimes farmers use mulching materials (e.g. water hyacinth, straw, banana leaf etc.) in their fields to keep the soil warm 
during winter and to protect soil from evaporation. Vegetable crop residues and mulching materials are in general enriched with $\mathrm{N}$ (Chaves et al, 2008) compared to rice crop residues. Logically the $\mathrm{C}: \mathrm{N}$ ratio of POM was found to be smaller in soils with vegetable-rice cropping pattern compared with the monoculture rice soils.

\section{Chemical $\mathbf{N}$ fractions}

The silt and clay fraction of SOM contained the majority of OC and $\mathrm{N}$ in the studied soils. This fraction was further fractionated into $\mathrm{NaOCl}$ oxidizable (NaOCl-ox), HF extracted (HF-ex) and HF resistant fractions (HF-res). The size of the OC and $\mathrm{N}$ fractions obtained from the chemical fractionation of silt and clay sized OM, expressed on a bulk soil basis ( $\mathrm{g} \mathrm{kg}^{-1}$ soil), is given in Table 2 . Briefly, the $\mathrm{NaOCl}$ oxidation removed substantially larger amount of $\mathrm{OC}$ and $\mathrm{N}$ from soils with vegetable-rice cropping pattern compared with their corresponding monoculture rice soils in all the four locations on a relative basis except Chandpur (Fig 2). On average, $\mathrm{NaOCl}$ oxidized significantly higher percentage of silt and clay sized $\mathrm{N}$ and $\mathrm{OC}$ for soils with a vegetable-rice cropping pattern (70 \pm 8 and $50 \pm 13 \%$ of silt and clay sized $\mathrm{N}$ and OC, respectively) compared with monoculture rice soils (54 \pm 8 and $40 \pm 9 \%$ of silt and clay sized $\mathrm{N}$ and OC, respectively). This result corresponds with Kader et al. (2010b) who found that $52 \pm 5 \%$ of the silt and clay sized $\mathrm{N}$ (i.e. $45 \pm 5 \%$ of soil $\mathrm{N}$ ) was oxidized by $\mathrm{NaOCl}$ in Belgian arable soils with a cereal-root crop rotation. $\mathrm{NaOCl}$ oxidation selectively removed larger amount of $\mathrm{N}$ compared with OC regardless of cropping pattern. The higher amount of $\mathrm{NaOCl} \mathrm{OC}$ and $\mathrm{N}$ in vegetable-rice soils suggests that SOM in vegetable-rice soils are more labile in character.

Subsequent mineral dissolution by $10 \% \mathrm{HF}$ released on average $49 \pm 18$ and $26 \pm 10 \%$ of NaOCl-res $\mathrm{N}$ and OC which is similar with the previously reported released of $48 \pm 12 \%$ of the NaOCl-res $\mathrm{N}$ by Kader et al. (2010b). HF extracted a smaller proportion of $\mathrm{N}$ and $\mathrm{OC}$ from vegetable-rice soils compared with the monoculture rice soils in all the four locations (Fig 2). However, the difference in HF-ex N and OC between soils from to land use group was not found to be significant. On an absolute basis, Rangpur was an exception (Table 2) and this could be due to the fact that in this location sometimes rice (transplant Aus rice) is cultivated during the fallow period succeeding to vegetables. Relative content of HF-res OC and $\mathrm{N}$ also followed the similar pattern in all the locations like the HF-ex OC and N (Fig 2). On average, HF-res OM represented $10 \pm 3$ and $25 \pm 5 \%$ of total $\mathrm{N}$ and SOC for the soils with vegetable-rice cropping pattern whereas it represented $17 \pm 4$ and $29 \pm 3$ of total $\mathrm{N}$ and SOC for rice soils. Higher proportion of HFresistant SOM in rice soils compared with soils from vegetable-rice cropping pattern may be due to the fact that there was more accumulation of lignin residues and $\mathrm{N}$ poor OM in monoculture rice soil. In rice monoculture two or three rice crop is cultivated per year and soil remains submerged for longer period which favoured accumulation of less humified SOM with larger molecules (Olk et al, 2000) and lignin residues in soils (Olk et al, 2002).

\section{CONCLUSIONS}

There is a shift in composition of SOM towards a more labile character in soils with vegetable-rice cropping pattern may be due to the farmer's practices keeping some crop residues and mulching materials in their fields after harvest. On the other hand, the nature of the SOM accumulated under rice monoculture is relatively more resistant with accumulation of lignin rich residues. However, the observed differences were not statistically rigorous as the soils were sampled from the farmer's fields where they did not 
maintain same cropping pattern and management practice every year. Intensively managed long term experimental soils could be the ideal one for such type of study.

\section{ACKNOWLEDGEMENTS}

M A Kader wishes to acknowledge the Flemish Inter-University Council (VLIR) for providing him a $\mathrm{PhD}$ grant to carry out this research.

\section{Literature cited}

Amelung, W. 1997. Zum Klimaeinfluß auf die organische Substanz nordamerikanischer Prärieböden. Bayreuther Bodenkundliche Ber. 53:1-140. (in German)

Carter, M.R. 2002. Soil quality for sustainable land management: organic matter and aggregation interactions that maintain soil functions. Agron. J. 94:38-47.

Chaves, B., De Neve, S, Boeckx, P., Van Cleemput, O. and Hofman, G. 2007. Manipulating nitrogen release from nitrogen-rich crop residues using organic wastes under field conditions. Soil Sci. Soc. Am. J. 71:1240-1250.

Chen, Q., Zhang, X.S., Zhang, H.Y., Christie, P., Li, X.L. and Horlacher, D. 2004. Evaluation of current fertilizer practice and soil fertilizer in vegetable production in the Beijing region. Nutr. Cycl. Agroecosyst. 69:51-58.

FAO, 2009. Statistical year book. (http://www.fao.org/economic/ess/publicationsstudies/statistical-yearbook/fao-statistical-yearbook-2009/en/)

Kader, M.A., Sleutel, S., D'Haene, K., De Neve, S. and Hofman G. 2010a. Limited influence of tillage management on organic matter fractions in the top layer of silt soils with a root-cereal crop rotations. Aus J. Soil Res. 48:16-26.

Kader, M.A., Sleutel, S., Begum, S.A., Jegajeevgan, K, D'Haene, K. and De Neve, S. 2010b. Soil organic matter fractionation as a tool for predicting nitrogen mineralization in silty arable soils. Soil Use Man. 26:494-507.

Lal, R. 2004. Agricultural activities and the global carbon cycle. Nutr. Cycl. Agroecosys. 70:103-116.

Lal, R. 2007. Carbon management in agricultural soils. Mitig. Adapt. Strat. Global Change. 12:303-322.

Leinweber, P. and Schulten, H. R. 1995. Composition, stability and turnover of soil organic matter: investigation by off-line pyrolysis and direct pyrolysis-mass spectrometry. J. Anal. Pyrol.32: 91-110.

Mikutta, R., Klebber, M., Torn, M. and Jahn, R. 2006. Stabilization of soil organic matter: association with minerals or chemical recalcitrance? Biogeochem. 77:25-56.

Olk, D.C., Dancel, M.C., Moscoso, E., Jimenez, R.R. and Dayrit, F.M. 2002. Accumulation of lignin residues in organic matter fractions of lowland rice soils: a pyrolysis-GC-MS study. Soil Sci. 167:590-606.

Olk,D.C., Brunetti G. and Senesi N. 2000. Decrease in humification of organic matter with intensified lowland rice cropping: A wet chemical and spectroscopic investigation. Soil Sci. Soc. Am. J. 64:1337-1347.

Reeves, D.W. 1997. The role of soil organic matter in maintaining soil quality in continuous cropping system. Soil Tillage Res. 43:131-167.

Sleutel, S., Leinweber, P., Begum, S.A., Kader, M.A. and De Neve, S. 2009. Shifts in soil organic matter composition following treatment with sodium hypochlorite and hydrofluoric acid. Geoderma. 149: 257-266.

Zhang, J.B., Song, C.C. and Yang, W.Y. 2006. Land use effects on the distribution of labile organic carbon fractions through soil profiles. Soil Sci. Soc. Am. J. 70:660-667 


\section{Tables}

Table 1 Selected soil properties of the sampled soils $(0-15 \mathrm{~cm}$ depth layer).

\begin{tabular}{|c|c|c|c|c|c|c|c|c|}
\hline \multirow{2}{*}{ Field } & \multirow{2}{*}{ Site } & \multicolumn{3}{|c|}{ Soil particles (g 100/g soil) } & \multirow{2}{*}{$\begin{array}{c}\text { OC } \\
\text { (g/kg soil) }\end{array}$} & \multirow{2}{*}{$\begin{array}{c}\text { TN } \\
\text { g/kg soil) }\end{array}$} & \multirow[t]{2}{*}{$\mathrm{C}: \mathrm{N}$} & \multirow[t]{2}{*}{$\mathrm{pH}_{\mathrm{KCl}}$} \\
\hline & & $>50 \mu \mathrm{m}$ & $2-50 \mu \mathrm{m}$ & $<2 \mu \mathrm{m}$ & & & & \\
\hline & Chandpur & & & & & & & \\
\hline 1 & Vegetable & 9 & 79 & 12 & 9.98 & 1.06 & 9.42 & 6.3 \\
\hline 2 & $\begin{array}{c}\text { Rice } \\
\text { Rangpur }\end{array}$ & 14 & 79 & 7 & 11.44 & 1.20 & 9.53 & 6.1 \\
\hline 3 & Vegetable & 27 & 60 & 13 & 9.95 & 0.96 & 10.36 & 5.8 \\
\hline 4 & $\begin{array}{c}\text { Rice } \\
\text { Bogra }\end{array}$ & 71 & 19 & 10 & 6.48 & 0.69 & 9.39 & 5.8 \\
\hline 5 & Vegetable & 19 & 65 & 16 & 12.35 & 1.50 & 8.23 & 5.9 \\
\hline 6 & $\begin{array}{c}\text { Rice } \\
\text { Netrokona }\end{array}$ & 17 & 48 & 35 & 13.20 & 1.38 & 9.57 & 5.7 \\
\hline 7 & Vegetable & 29 & 62 & 9 & 8.13 & 0.76 & 10.70 & 5.8 \\
\hline 8 & Rice & 28 & 52 & 20 & 10.72 & 1.24 & 8.65 & 5.8 \\
\hline
\end{tabular}


Table 2 Amounts of total $\mathrm{N}$ ( $\mathrm{g} \mathrm{N} \mathrm{kg} \mathrm{soil}{ }^{-1}$ ) and C:N ratios of the isolated physicochemical fractions (average \pm standard deviation) .

\begin{tabular}{|c|c|c|c|c|c|c|c|c|c|}
\hline \multirow{4}{*}{ Field: } & \multirow{4}{*}{ Site } & \multirow{3}{*}{\multicolumn{2}{|c|}{$\begin{array}{l}\text { Particulate } \\
\text { OM (POM) }\end{array}$}} & \multicolumn{6}{|c|}{ Silt and clay fractions } \\
\hline & & & & \multirow{2}{*}{\multicolumn{2}{|c|}{$\begin{array}{l}\mathrm{NaOCl} \text {-oxidizable } \mathrm{OM}- \\
(\mathrm{NaOCl}-\mathrm{ox})\end{array}$}} & \multicolumn{4}{|c|}{$\mathrm{NaOCl}$-resistant OM } \\
\hline & & & & & & \multicolumn{2}{|c|}{$\begin{array}{c}\text { Extracted by HF OM } \\
(\text { HF-ext })\end{array}$} & \multicolumn{2}{|c|}{$\begin{array}{c}\text { HF-resistant OM } \\
\text { (HF-res) } \\
\end{array}$} \\
\hline & & \multirow[t]{2}{*}{$\mathrm{N}$} & \multirow[t]{2}{*}{$\mathrm{C}$} & $\mathrm{N}$ & $\mathrm{C}$ & $\mathrm{N}$ & $\mathrm{C}$ & $\mathrm{N}$ & $\mathrm{C}$ \\
\hline & Chandpur & & & & & & & & \\
\hline 1 & Vegetable & 0.43 & 4.96 & $0.49 \pm 0.07$ & $3.21 \pm 0.41$ & $0.07 \pm 0.05$ & $0.18 \pm 0.09$ & $0.10 \pm 0.04$ & $2.06 \pm 0.62$ \\
\hline \multirow[t]{2}{*}{2} & Rice & 0.28 & 3.49 & $0.54 \pm 0.11$ & $3.68 \pm 0.51$ & $0.06 \pm 0.03$ & $0.62 \pm 0.23$ & $0.28 \pm 0.06$ & $3.01 \pm 0.66$ \\
\hline & Rangpur & & & & & & & & \\
\hline 3 & Vegetable & 0.14 & 2.07 & $0.56 \pm 0.01$ & $2.55 \pm 0.12$ & $0.17 \pm 0.09$ & $1.55 \pm 0.45$ & $0.14 \pm 0.07$ & $3.12 \pm 0.56$ \\
\hline \multirow[t]{2}{*}{4} & Rice & 0.17 & 1.81 & $0.23 \pm 0.03$ & $1.54 \pm 0.16$ & $0.15 \pm 0.02$ & $1.02 \pm 0.13$ & $0.11 \pm 0.01$ & $1.81 \pm 0.21$ \\
\hline & Bogra & & & & & & & & \\
\hline 5 & Vegetable & 0.28 & 3.19 & $0.68 \pm 0.09$ & $3.77 \pm 0.45$ & $0.29 \pm 0.14$ & $1.50 \pm 0.46$ & $0.11 \pm 0.05$ & $3.21 \pm 0.52$ \\
\hline \multirow[t]{2}{*}{6} & Rice & 0.15 & 3.63 & $0.51 \pm 0.13$ & $2.87 \pm 0.64$ & $0.37 \pm 0.08$ & $2.16 \pm 0.41$ & $0.21 \pm 0.05$ & $4.41 \pm 0.71$ \\
\hline & Netrokona & & & & & & & & \\
\hline 7 & Vegetable & 0.10 & 1.95 & $0.46 \pm 0.01$ & $3.75 \pm 0.11$ & $0.05 \pm 0.04$ & $0.46 \pm 0.19$ & $0.07 \pm 0.03$ & $1.75 \pm 0.47$ \\
\hline \multirow[t]{2}{*}{8} & Rice & 0.20 & 3.04 & $0.54 \pm 0.07$ & $3.23 \pm 0.42$ & $0.18 \pm 0.04$ & $1.20 \pm 0.24$ & $0.19 \pm 0.03$ & $3.13 \pm 0.49$ \\
\hline & Mean & & & & & & & & \\
\hline & egetable & 0.24 & 3.05 & 0.55 & 3.32 & 0.05 & 0.92 & 0.11 & 2.54 \\
\hline & Rice & 0.20 & 2.99 & 0.46 & 2.83 & 0.18 & 1.25 & 0.20 & 3.09 \\
\hline & ANOVA & NS & NS & $*$ & NS & NS & NS & $*$ & NS \\
\hline
\end{tabular}




\section{Figures}

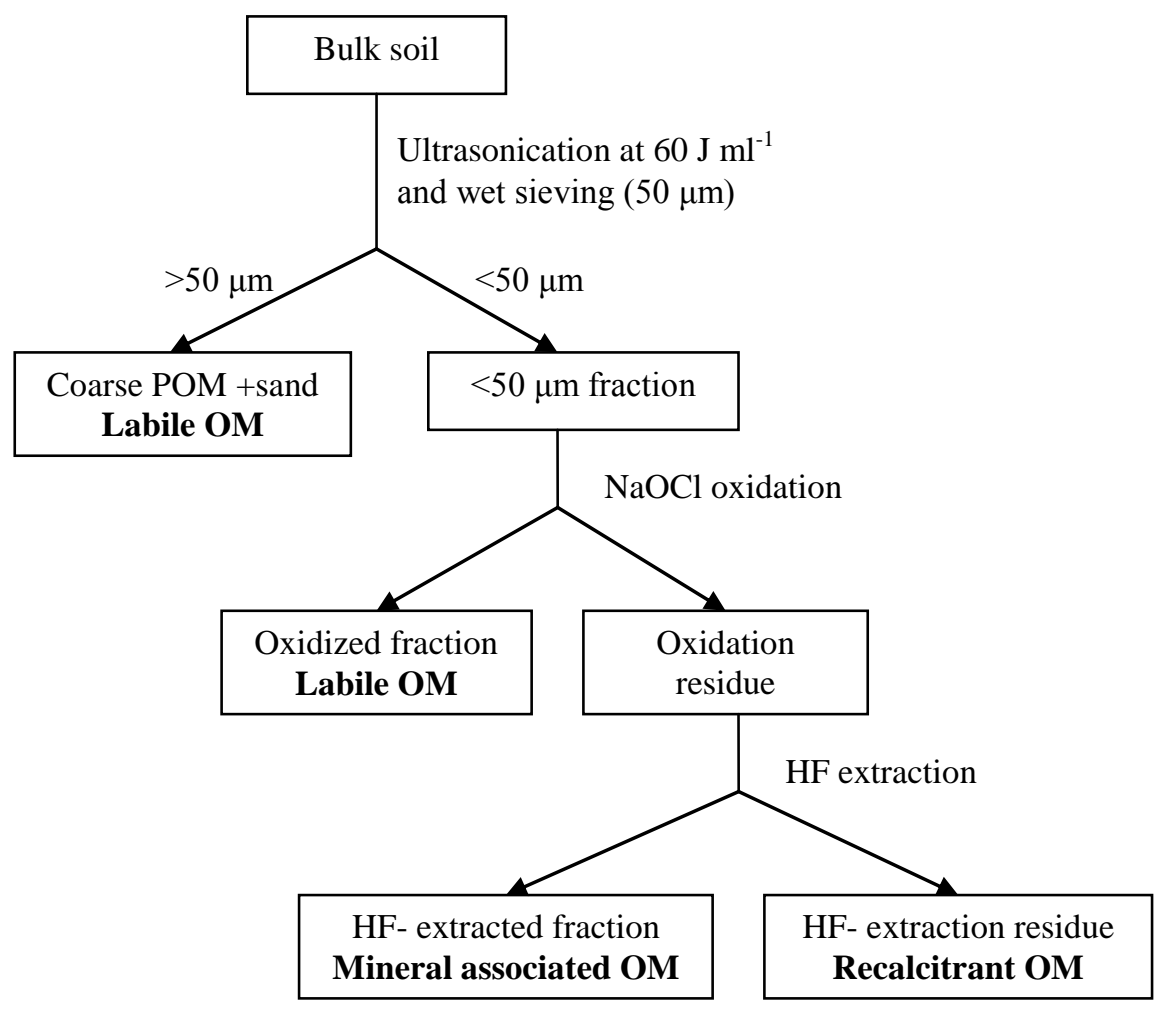

Figure 1. Combined Physical and chemical fractionation Scheme to isolate labile, mineral protected and recalcitrant organic matter. 


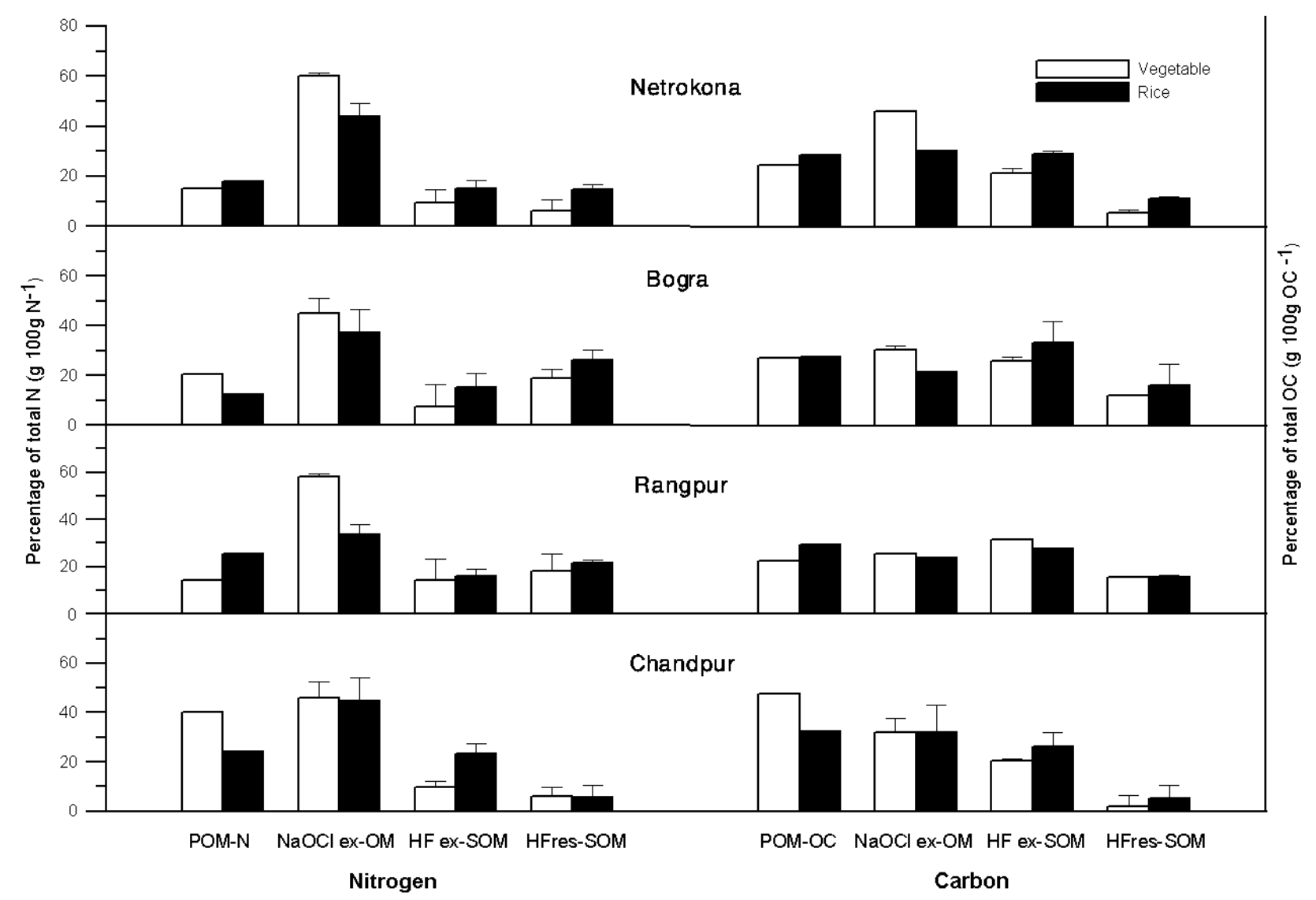

Figure 2. Relative distribution of the total N (left) and OC (right) over different SOM fractions for the vegetable-rice and rice-rice cropping pattern 